\title{
On the Theory of Entrepreneurial Incentives and Alertness
}

\author{
Matthew McCaffrey
}

This paper analyzes the theory of "entrepreneurial incentives" in the work of Israel Kirzner. It argues that there is a logical problem with the notion of profit opportunities as exogenous causal agents: Without additional assumptions, the existence of opportunities alone does not sufficiently explain the alertness of entrepreneurs. The paper considers both stronger and weaker versions of this problem. It also questions the relation between entrepreneurial incentives and the tendency toward entrepreneurial success. Finally, it provides some commentary on the relevance of entrepreneurial incentives for an overall theory of the entrepreneur, and identifies several potential solutions to the problems discussed.

\section{Introduction}

Professor Israel Kirzner advances a specialized theory of incentives as a component of his theory of the entrepreneur. The main purpose of this paper is to examine critically this theory of "entrepreneurial incentives." I emphasize at the outset the open-ended nature of this discussion: I wish to dispute several of Kirzner's claims based upon their own internal consistency, and not simply to contrast his theory with others. The Kirznerian position, I argue, contains weaknesses of its own regardless of possible comparative deficiencies.

Because it is not tied to any particular view of entrepreneurship, this discussion is useful from the perspective of many different theories. Further, given the importance of Kirzner's work in the existing literature on opportunity, alertness, and discovery (Alvarez \& Barney, 2007; Chandler, DeTienne, \& Lyon, 2003; Shane, 2000; Shane \& Venkataraman, 2000), and Kirzner's own trepidation concerning the widespread understanding of his theory (Kirzner, 2009), a critical examination may prove constructive, especially for those interested in the opportunity-discovery approach. In particular, literature that focuses on alertness as a primary component of entrepreneurship must take note of Kirzner's special theory of entrepreneurial incentives, which is the very foundation of his view of alertness, and must be clearly understood if his work is to represent anything more than a vestigial citation.

Recent literature has stressed that the antecedents of entrepreneurship (i.e., entrepreneurial incentives) remain largely undefined (Foss \& Klein, 2010; Valliere, 2011). A secondary purpose of this paper is to explain the origin of the confusion regarding the

Please send correspondence to: Matthew McCaffrey, tel.: (970) 214-5078; e-mail: Mcm0016@gmail.com. 
antecedents of alertness, stemming from the work of Kirzner, whose research remains one of the original primary sources on entrepreneurial alertness. Another minor purpose is to explain how this particular problem is recognized and addressed in the current literature, and how it might be solved.

This paper is structured as follows: The second section distinguishes between a stronger and weaker form of Kirzner's theory of entrepreneurial incentives, and points out difficulties with the strong version. The strong version posits a direct causal link between the existence of opportunity and the discovery of opportunity by entrepreneurs. The distinction between strong and weak forms is necessary because it highlights the difference between the core problem of entrepreneurial incentives and Kirzner's own attempts to avoid this problem. The distinction also helps place Kirzner in the context of contemporary literature, showing the relevance of entrepreneurial incentives for current research. In order to show why he believes a theory of entrepreneurial incentives is necessary, I will also mention Kirzner's own views about standard incentive theory in neoclassical economics. The third section explains and criticizes the more elaborate weaker version of the theory, arguing that it too contains logical difficulties. The weaker version also argues for a connection between opportunity and alertness, but is qualified to include several different kinds of explanation for that connection. The fourth section outlines two types of solution to the problems of Kirzner's theory: first, through the opportunity discovery literature, and second through the opportunity creation approach to entrepreneurship. The final section provides concluding remarks.

\section{The Theory of Entrepreneurial Incentives}

The essence of Kirzner's general theory of entrepreneurship may be found in Kirzner $(1973,1979,1985) .{ }^{1}$ In this view, entrepreneurship consists in the perception of previously unnoticed profit opportunities, where "opportunities" are essentially synonymous with arbitrage possibilities. The entrepreneur is "alert" to these opportunities, and his alertness enables him profitably to discovery them. A component of Kirzner's theory-an implication of the concept of alertness - is a distinction between the incentives faced by entrepreneurs and those faced by other economic actors. The theory of entrepreneurial incentives is most fully and clearly formulated in Kirzner (1985), although the argument is interwoven throughout his works.

In an early presentation, Kirzner distinguishes between standard maximization behavior and entrepreneurial behavior, and uses this distinction to discuss what he considers the essence of entrepreneurship (Kirzner, 1973). The foundations of entrepreneurial behavior are not addressed much, however, with the focus instead on their results: the competitive and equilibrating market process. In a later exposition though (Kirzner, 1985), Kirzner attempts to more fully explain the sources of entrepreneurial alertness, and he casts the distinction between maximizing and entrepreneurial behavior in terms of two different types of incentives. As will be shown, "entrepreneurial incentives" are a vital concept for Kirzner's notion of alertness, hence my discussion of a "theory of entrepreneurial incentives," which is part and parcel of the theory of alertness. In fact, it is the foundation of alertness in Kirzner's work.

Incentives for Kirzner appear in two broad classes: incentives that motivate "ordinary" action and those that inspire entrepreneurial alertness. Incentives in the first sense are

1. Many elaborations and clarifications are collected in Kirzner (2000). 
taken as "referring to the provision of an encouragement for a decision maker to select a particular one out of an array of already perceived alternatives" (Kirzner, 1985, pp. 94-95; emphasis in original). Incentives of this type motivate the behavior of standard maximization models in neoclassical microeconomics, or what Kirzner refers to as "Robbinsian maximizing." Incentives are essentially courses of action with known costs and benefits, and as such are the motivating forces behind economic behavior. An actor perceives different courses of action, and incentives alter the actor's appraisal of the value of these potential actions. This entails the shifting of the opportunity-cost relationship, which will in turn inform the actor's choice (Kirzner, pp. 94-96). This much is consistent with the approach to incentives found in much of the economics literature. ${ }^{3}$ According to Kirzner, this view of incentives is the dominant one in economics, and is an incomplete view as well: He claims that by focusing only on "already perceived alternatives," economists miss another important type of incentive- the incentive that inspires entrepreneurial alertness and discovery.

The purpose of the theory of entrepreneurial incentives is to explain how entrepreneurship can be discussed in terms of incentives, which are typically a matter of costs and benefits. A behavior that does not have costs and benefits - as is the case with entrepreneurship in Kirzner's view-cannot then be described in terms of incentives in the usual sense. Kirzner's "entrepreneurial incentives" describe how an entrepreneur moves from a passive state to a state of alertness without possessing specialized knowledge or traits, and perhaps more importantly without engaging in search efforts. Once in the alert state, the entrepreneur is capable of discovering and evaluating previously hidden profit opportunities, which for Kirzner is the essence of the entrepreneurial function. Alertness can be briefly summarized as "the ability to notice without search opportunities that have been hitherto overlooked" (Kirzner, 1979, p. 148; emphasis added). ${ }^{4}$

According to this theory, entrepreneurial incentives are an entirely different kind than the incentives involved in standard utility maximization. Entrepreneurial alertness does not entail the use of resources, and is therefore not scarce in the usual sense. For the same reason, it also involves no cost. It cannot then be described in terms of ordinary incentives, which explicitly refer to scarcity and cost relations. Whereas ordinary incentives involve the weighing of opportunities that have already been perceived, entrepreneurial incentives refer to the process of making previously unforeseen opportunities visible to entrepreneurs. Opportunities are essentially price differentials, possibilities for arbitrage from which entrepreneurial profit derives (Kirzner, 1973). The arbitrage process is, however, a result of entrepreneurial alertness and discovery, while this paper is concerned with the incentives that inspire alertness in the first place.

Instead of altering the opportunity cost of perceived options, entrepreneurial incentives refer to opportunities that would be the most highly valued, but which are currently unnoticed:

2. Cf. Kirzner (1973, pp. 32-37) for an explanation of this view. As a historical aside, Salerno (2009) argues that Robbins did not endorse the narrow theory of utility maximization that Kirzner describes, but rather a theory closer to Kirzner's own view.

3. Note that Kirzner's approach to ordinary incentives is a qualitative, theoretical one. He is not concerned with the empirical problem of which particular things motivate action. To avoid confusion, I also distinguish between incentives in a "broad" and "narrow" sense of the term. Incentives in the broad sense refer to the set of all things potentially valued by economic actors. This is the way Kirzner uses the term. Incentives in the narrow sense refer to agency relationships, where incentives of the first kind are restricted to a principal-agent contract. For incentives in the narrow sense, cf. Laffont and Martimort (2002).

4. What matters in explaining entrepreneurial alertness is not whether an opportunity is actually profitable. What matters is the belief that it is profitable (Kirzner, 1985, p. 7). 
There is no need to offer incentives in order to overcome the opportunity cost of rejecting course of action $B$. $A$ is already offering greater rewards than $B \ldots$. [A]ny . . . sweetening .... of the anticipated value of the consequences of undertaking $A$ does not affect action through the enhancement of the relative desirability of $A$. Rather, the incentive to undertake $A$ operates, under the specified assumptions, through its inducement to discover the possibility and/or the attractiveness of $A$. (Kirzner, 1985, p. 96; emphasis in original)

Kirzner is quite explicit that discovery is not a deliberate search for advantageous opportunities. Deliberate search would simply reflect incentives of the ordinary kind (Kirzner, 1985, pp. 96-97). The alert individual is rather a passive participant in this process. The entrepreneur's alertness is triggered by the existence of the incentive; alertness does not seek out the incentive. Based upon this chain of reasoning, Kirzner provides a method of explaining all economic behavior in terms of at least one of the two kinds of incentives.

However, Kirzner also identifies a major difficulty with this approach: the problem of causation between opportunity and alertness. His argument strongly implies that profit opportunities stand in a causal relation to entrepreneurial alertness. We can distinguish both a strong and a weak version of this causation. The strong version of the theory simply states that profit opportunities cause their own discovery. Kirzner identifies the paradox:

How, one must surely ask, can an enhancement of the desirability of a particular course of action which by the very definition of this kind of incentive has not yet been noticed inspire its discovery? How can an unnoticed potential outcome, no matter how attractive, affect behavior? How can the attractiveness of an unknown opportunity that awaits one around the corner possibly inspire one to peer around that corner? (Kirzner, 1985, pp. 108-109; emphasis in original)

This dilemma is significant. Without anthropomorphizing profit opportunities, it is difficult to see how we could speak of an inanimate entity (profit opportunity) causing itself to be noticed by an individual who is not searching for it, and especially by particular individuals and not others. Kirzner's honest but surprising response to these difficulties is to remark:

It would be presumptuous and misleading to suggest that I know the answer to these questions. We do not know ... precisely how human beings are inspired by the attractiveness of unknown opportunities. But there can be no doubt that such inspiration has been of enormous importance throughout recorded human history ... Yet we know that the driving force behind this energy and this alertness is firmly rooted in the nature of the unknown-precisely the opposite of the economic motivations that govern nonentrepreneurial endeavor. (Kirzner, 1985, p. 109)

It may certainly be true that much work has yet to be done in understanding human inspiration. But Kirzner has not shown at all that his specific opportunity incentive theory is in any way related to the historical inspiration he mentions, either generally or for entrepreneurs specifically. The above passages take the inspiration that occurred "throughout recorded human history" as synonymous with Kirzner's entrepreneurial incentive theory. But no connection has been established, either theoretically or empirically. The phrases "there can be no doubt" and "yet we know" in the above do not in fact reflect any knowledge provided to us by Kirzner's argument. He has avoided answering the question on which his theory rests, which appears to contain a logical inconsistency: the problem 
of the causal factors behind alertness, that is, entrepreneurial incentives. Thus, explanation of how "ignorant entrepreneurs learn what they need to know (let alone interpret it correctly), so as to make a profit, is, at best, a non-explanation: they are 'alert' to profit opportunities, hence they notice them, hence they know what to do about them" (Evans \& Friedman, 2011).

Kirzner (2009) explicitly recognizes that it is not the goal of his work to identify the secrets of entrepreneurial success, or enumerate those factors that stimulate alertness. ${ }^{5}$ Rather, his aim is to explain the consequences of alertness; the qualitative economic relations that constitute the entrepreneurial market process. Nevertheless, one of these qualitative relations is the one between entrepreneurial alertness and entrepreneurial incentives, which is vital in explaining the foundations of the market process, and must therefore be carefully examined. It is not sufficient to simply assume that the relation exists, and simply to pass on to its implications. And it is here that Kirzner's exposition appears incomplete. Having examined the fundamental issue at stake in the theory, we can now proceed to discuss a weaker version, which may prove more successful.

\section{Profit Opportunities as Exogenous Causal Variables}

\section{The Relevance of Entrepreneurial Incentives and Alertness for Contemporary Research}

The second section described the most literal reading of Kirzner's argument. In the interest of being as fair as possible though, it might be argued that Kirzner uses the word "cause" in a broader (or perhaps, "weaker") sense than the one described above. Specifically, he may mean that the existence of an opportunity is merely a part of the reason for an entrepreneur noticing it, along with other significant explanatory objects. As opposed to postulating that opportunities cause discovery by themselves, with no other considerations, perhaps Kirzner means that there are other explanations that link opportunity to discovery in a causal manner. These other explanations might simply be included under a broader definition of "opportunity." This reading is supported in Kirzner's writing: "However little we know about the ways different entrepreneurs discover what they discover, almost all such discoveries would not be made were there not the possibility of personally attractive, desirable outcomes" (Kirzner, 1985, p. 87). The implication of this quotation appears to be that the objective existence of an opportunity explains in part why it is noticed, but that there are other facts that combine with the existence of opportunity to explain discovery. Indeed, Kirzner provides many possible explanations of the other components of opportunity that cause awareness. This section will explore these other components in order to determine whether this weaker version can support the theory of entrepreneurial incentives.

The literature inspired by Kirzner (as referenced throughout this paper) is certainly more interested in the weaker approach, involved as it is with questions of search, knowledge, costs, and so on. If we are to test the relevance of Kirzner's theory, however,

5. In the article cited here, Kirzner appears to conflate two distinct problems: the problem of entrepreneurial alertness and the problem of entrepreneurial success. Alertness is merely the ability to discover, while success is the discovery of a particular, definitely existing, profitable opportunity. Kirzner's comment that he does not seek to explain alertness seems directed only at the second problem. His comments regarding alertness, many quoted in the present paper, indicate that he does in fact have something to say about its causes. 


\author{
Opportunity discovery \\ Opportunity creation \\ Alertness \\ Search \\ Spontaneous learning/awareness of opportunities \\ (characterized by some authors as "luck") \\ Specialized knowledge structures
}

\author{
Yes; opportunities exist in the world, waiting for entrepreneurs to discover them. \\ No; entrepreneurs perceive what already exists, but has so far gone unnoticed. \\ Yes; entrepreneurship is the discovery of opportunity, and discovery is spontaneous, \\ not planned (if it could be planned, it could be accounted for in advance). \\ No; search implies that individuals are already aware of opportunities, so the \\ alert entrepreneur cannot search by definition. \\ Yes; because entrepreneurs cannot search, they must be made aware of \\ opportunities by the opportunities themselves. \\ No; if entrepreneurs possessed specific knowledge, they would be actively \\ searching, not passively alert to opportunities.
}

each of these ways of looking at alertness must also be understood in light of entrepreneurial incentives, which Kirzner insists are at the root of alertness. What is more, some authors argue that the concept of alertness (and its relation to other fundamental concepts) "lack[s] a clear theoretical underpinning" (Valliere, 2011). Clarifying the relation of these problems to entrepreneurial incentives is, therefore, an important task.

To begin, it is important to position Kirzner's work in light of some prominent themes in contemporary entrepreneurship research. Table 1 lists several relevant themes in entrepreneurial studies, and briefly summarizes their relation to the Kirznerian approach. Each entry states simply whether the concept is included in Kirzner's theory and provides a short explanation of Kirzner's reasoning. The important point is that Kirzner's theory is one of opportunity discovery, alertness, and spontaneous learning, and not one of opportunity creation, search efforts, or the use of previously acquired knowledge.

Further details of Kirzner's approach and my criticism of it are reserved for later sections. For the moment, I will simply point out that serious study of Kirzner's theory of alertness is important, given that his work is often cited in the literature. However, some studies have characterized the theory in unintentionally confusing or inconsistent ways. In addition to being important in their own right, these views of Kirzner will also help inform later discussions of how to avoid some of the problems of Kirzner's theory. The rest of this subsection briefly explores the conceptual and empirical context in which Kirzner's theory has been evaluated. Specifically, it discusses how the notion of entrepreneurial incentives (and hence, alertness) is addressed, conceptually and empirically.

Table 2 categorizes some of the most relevant literature and its relationship to Kirzner's work. Row 1 mentions some common readings of Kirzner's work that have accidentally attributed to it characteristics that conflict with its original intent. The purpose of this summary is not to criticize these studies, especially because their purpose is often not a detailed exegesis of Kirzner's work. Furthermore, the research mentioned often moves considerably beyond Kirzner's: As I discuss in the Problems and Solutions section, many of them develop sophisticated responses to the problems I raise here. I merely wish to point out how easy it is to develop a wide range of interpretations of Kirzner. 


\section{Table 2}

\section{Kirzner and Entrepreneurial Incentives in Entrepreneurship Research}

Studies implying that Kirzner's theory invokes specific knowledge, search efforts, and/or information-seeking

Experimental studies that fail to find strong evidence in favor of entrepreneurial incentives

Studies that avoid Kirzner's "paradox" by altering his fundamental approach

\section{Search}

Kaish and Gilad (1991): Alertness is a more general type of search, and entrepreneurs "position" themselves with regard to opportunities.

Tang et al. (2008): There is no deliberate search in Kirzner, but there is still information-seeking behavior.

Tang et al. (2012): Kirzner's theory is consistent with the claim that scanning and search are part of alertness. Systematic search is not consistent with Kirzner, but nonsystematic searches can be.

Herron and Sapienza (1992): Search leading to discovery is the essence of entrepreneurship according to Kirzner (although some element of spontaneity exists).

\section{Knowledge}

Busenitz (1996): Information and information-seeking behavior are the central tenets of alertness

Shane (2000): Entrepreneurs are alert because they have access to (prior) knowledge that is distributed asymmetrically.

Jacobson (1992): Entrepreneurs and firms use particular, superior information to discover opportunities.

Demmert and Klein (2003)

Kitzmann and Schiereck (2005)

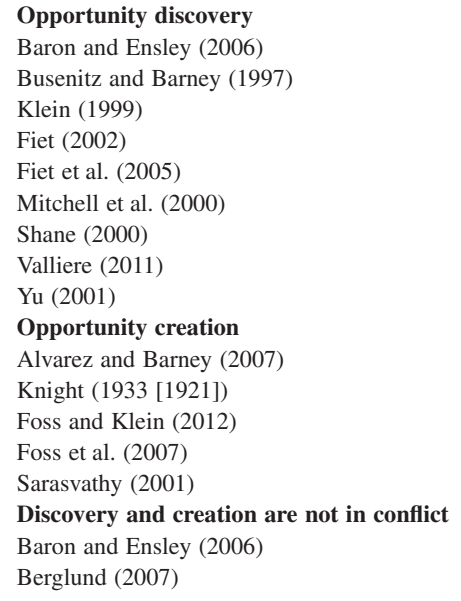

For example, stemming largely from the empirical work of Kaish and Gilad (1991), multiple sources associate Kirzner's theory with the possession of specific knowledge and/or some type of search behavior, where at the very least entrepreneurs "position" themselves advantageously in regard to possible opportunities. This is perhaps why many studies seek to alter the foundations of Kirzner's theory without noting the departure they make from Kirzner's position. Tang, Tang, and Lohrke (2008) avoid attributing the idea of search to Kirzner, recognizing his notion of entrepreneurial incentives, but nevertheless claim that seeking information is the "central tenet" of Kirzner's notion of alertness. And Tang, Kacmar, and Busenitz (2012) go a step further, arguing that it is consistent with Kirzner to include varieties of search as major components of alertness. In their view, even if systematic search is excluded, searching in nonsystematic ways is an aspect of alertness. Herron and Sapienza (1992) further mention that although discovery is spontaneous, it is also intertwined with search. 
It is also not uncommon to discuss Kirzner in connection to the possession of knowledge or knowledge structures (Mitchell, Smith, Seawright, \& Morse, 2000). Busenitz (1996) states that Kirzner "posited information and information-seeking behavior as the central tenants [sic] of entrepreneurial alertness." Shane's (2000) study considers Kirzner's theory of alertness to be compatible with or directly invoke the idea of already-acquired knowledge. And Jacobson (1992) argues that entrepreneurs and firms in Kirzner's theory use superior individual knowledge to discover opportunities. McMullen and Shepherd (2006), to some extent, also associate Kirzner's entrepreneur with preexisting knowledge, although their position is less clear, and their study also notes some problems in Kirzner's notion of entrepreneurial motivation. ${ }^{6}$

Beyond conceptual studies, research has also attempted to test the existence or prevalence of entrepreneurial incentives and alertness (row 2 of Table 2). Typically, tests of Kirzner's theory focus on alertness after it already exists, after the entrepreneur's "antennae" have already been switched on to the possible existence of opportunities. Fiet and Patel (2008), for example, perform this kind of experiment, finding that preexisting specific knowledge plays an important role in the discovery of profitable ventures, whereas alertness by itself produces far less profitable ideas.

Although alertness can be approached from many angles, what is empirically relevant for this study is the question whether it is possible to test if alertness emerges in the manner described by Kirzner: as the result of only the existence of opportunities. Seen in the context of an experiment then, the oddness of the Kirznerian approach becomes apparent. Testing alertness is a difficult task, especially because it is difficult to measure (Busenitz, 1996; Tang et al., 2012). To test the Kirznerian alertness hypothesis, experiments must be able to provide an environment in which a profitable opportunity exists, but is unknown to the participant-entrepreneur. The more specific the opportunity (known only to the designers of the experiment), presumably the easier it will be to isolate its effects on the subjects in order to determine whether there is anything like a causal relation between the opportunity and its discovery. However, the subjects of the experiment must be without special characteristics that might enable them to leave their state of passive non-alertness, for example, to search.

It should come as no surprise that constructing such an experiment is extremely difficult. This fact by itself should give empirical researchers some pause: If opportunities, alertness, and the causal relation between them are as ubiquitous as Kirzner appears to believe, why are these conditions so difficult to simulate? Nevertheless, some studies have attempted to do just this.

Demmert and Klein (2003) design an experiment to model an environment where invisible and unknown profit opportunities stimulate alertness in individuals who are not looking for them. They assigned the participants (students) the task of transferring quantities of water from a full bucket to a separate, empty one, and informed the students that financial rewards would be larger the more water the students could successfully transfer. Students were given a stool, on which were set small containers of various sizes to be used in the transfer. They were limited in the time allowed for completing the transfer ( 3 minutes), and could only make one trip between the full and empty buckets, neither of which they were permitted to move. Each of the small containers contained less capacity than that corresponding to the maximum possible monetary reward. The hidden opportunity lay in the fact that the stool on which the cups and water were set could be

6. McMullen and Shepherd (2006) do note that Kirzner's theory is essentially one of passivity and must be integrated with other types of theory before it can become a theory of entrepreneurial action. 
turned upside down, rendering it into a container with the largest capacity of those available. The opportunity, thus, existed objectively, but was unknown to the students, who did not know there was even something to search for, only that they would be rewarded according to how much water they transferred. According to Kirzner's theory, it was in the student's interest to notice the opportunity, and therefore they should have tended to notice it.

The results of the test, however, failed to confirm Kirzner's hypothesis. Most students did not perceive the opportunity, despite it being in their direct interest to do so. There were difficulties, however, in conveying just the right sort of information to the participants. The assumptions of Kirzner's theory make it extremely difficult to create an environment in which the appropriate preconditions are satisfied, especially in regard to limiting students' ability to engage in search efforts.

Nevertheless, this is to date the most explicit attempt to test the theory of entrepreneurial incentives and "inspired" alertness. ${ }^{7}$ Despite the limitations of this first effort, a similar experiment was conducted by Kitzmann and Schiereck (2005). In this study, some of the imperfections of the original experiment were addressed through greater precision in the preparation work. Although more supportive of Kirzner's theory than the original, the results still showed only a weak connection between opportunity and alertness. In other words, there was only a weak form of entrepreneurial incentive present, with large groups either failing to discover the opportunity altogether or approaching it through traditional problem solving skills (i.e., through ordinary incentives). In fact, most students $(78.8 \%)$ who did perceive the opportunity noted that they used deliberate search methods.

The experimental record does not, thus far, lend much support to Kirzner's theory, although existing studies do provide promising routes for future research. ${ }^{8}$ Although future experiments need not take the form of those mentioned above, they do need to take great care to distinguish between genuine Kirznerian alertness if and when it happens, and any sort of response to ordinary incentives. The problem remains to structure experiments that truly do test discovery, as opposed to simply testing search efforts (Kitzmann \& Schiereck, 2005). The difficulties in doing this in simple experiments indicate that with greater levels of complexity, and lower degrees of design control, problems may be even more significant. This is further supported by Patel and Fiet (2010), who argue that experiments in entrepreneurship experience great difficulty in accounting for different types of heterogeneity in the behavioral setting and in creating something like a closed environment. In addition, the specific uncertainties inherent in entrepreneurship make it necessary to vary both the type of experiment and the test population. Otherwise, it is quite difficult to generalize the results.

However, as I show elsewhere in this paper, Kirzner's position is simply the logical outcome of his fundamental assumptions about entrepreneurial behavior. Its difficulties lie deeper than the present inability to confirm it experimentally. The logical problem of opportunities inspiring their own discovery must be addressed in addition to any empirical problems of the theory.

7. The author was unable to discover any experimental tests of entrepreneurial incentives that confirmed Kirzner's theory.

8. One might observe, without irony, that research into Kirzner's theory may itself be a test of it. That is, if it is profitable to discover creative new ways to experiment with alertness, we should expect an expanding literature on this topic. For an overview of promising experimental methods in entrepreneurship, cf. Patel and Fiet (2010). 


\section{A Further Look at Entrepreneurial Incentives and Alertness}

A vital point of Kirzner's theory is that it supposes that entrepreneurial incentives are exogenous causal agents that influence alertness without any special action or knowledge on the part of the entrepreneur. This is precisely the difference between the two types of incentives - one is the object of purposeful human behavior while the other is imposed upon human behavior.

The exogenous nature of entrepreneurial incentives leads to a difficulty with the weaker approach to incentives. Specifically, if the reality of the opportunity-the objective "truth" of its existence-is a factor in whether it is noticed, it is not clear how one can distinguish between individuals who are more or less capable of noticing it. That is, unless we posit the superior knowledge or alertness of certain individuals, this explanation reduces simply to the stronger causal claim discussed in the The Theory of Entrepreneurial Incentives section. Remember that Kirzner's entrepreneur is passive ${ }^{9}$ prior to being made alert. This subsection will analyze the many different ways out of this dilemma that Kirzner proposes. Because these various methods revolve around similar themes, there is some degree of repetition in the argument. I also note that I discuss these alternatives within the context of Kirzner's own theory and its internal logical consistency.

The first possibility, rejected by Kirzner, is that alertness is a choice of the entrepreneur. But one cannot simply choose to be alert, for this would presuppose alertness (Kirzner, 1979, pp. 30-31). Next, consider the prospect that entrepreneurs simply search for opportunities. Importantly, search is explicitly rejected by Kirzner because search is a part of ordinary incentive arrangements (Kirzner, 1985, pp. 96-97, 132-133), which cannot be expressed in terms of his theory of alertness. The impossibility of search is significant because existing literature that incorporates Kirzner's theory sometimes includes search as an important component of discovery (Fiet, 2002, 2007; Fiet, Piskounov, \& Patel, 2005; Shane, 2003, pp. 48-49; Zahra, 2008). There appears to be some confusion on this issue. Herron and Sapienza (1992), for instance, claim that at the heart of Kirzner's theory is the idea that opportunity implies search, despite Kirzner's insistence to the contrary: Kirzner makes this point quite clear, whether we accept his conclusion or not. Given his opposition, it is questionable whether Kirzner should be included in this branch of the literature.

Likewise, additional knowledge on the part of the entrepreneur is also dismissed as a source of alertness (Kirzner, 1997a). On this point, it is important to carefully distinguish between the already-alert entrepreneur and the initial causes of alertness. An entrepreneur already in a state of alertness possesses "not so much the substantive knowledge of market data as [he possesses] alertness, the knowledge of where to find market data" (Kirzner, 1973, p. 67; emphasis in original). But where does this general knowledge come from? Kirzner implies that it is a feature of all human behavior: "[T]he human agent is at all times spontaneously on the lookout for hitherto unnoticed features of the environment ... which might inspire new activity" (Kirzner, 1997a). If all action involves this type of general knowledge, or if all individuals are always alert, the theory is back at the start; we have no explanation as to how alertness happens. Because everyone is always alert, everyone possesses the general knowledge of opportunity. But then the concept of an

9. Kirzner (2009) addresses criticisms of his work that claim that his "passive" entrepreneur eliminates the vigorous personal characteristics that characterize the Schumpeterian entrepreneur, downplaying the role of creation and innovation, or ignoring personal characteristics so as to focus on an economic function. This is not my point, however. I wish to observe that Kirzner insists that entrepreneurial incentives influence alertness from without, absent any entrepreneurial effort. Subsequent creation, innovation, leadership, etc. is beside the point. 
entrepreneurial incentive seems to disappear because there are no non-alert individuals. General knowledge might enable the already-alert entrepreneur to successfully identify profit opportunities. But it does not explain the incentive problem: how the entrepreneur came to be alert in the first place, or the problem of how some individuals notice opportunities while others do not. Differences in knowledge (especially errors) create opportunities (Kirzner, 1973, pp. 14, 66-67, 216), but they do not cause alertness in a way that would free Kirzner's theory from difficulty.

Kirzner (2005) elaborates some of his ideas on knowledge, drawing a distinction between "information-knowledge" and "action-knowledge." The former refers to information that may relate to an opportunity, but is not actionable because it has not been realized by the individual. "Action-knowledge," on the other hand, has already been processed enough to be able to support entrepreneurial discovery. Even if two individuals may possess the same information, only one who is sufficiently alert can make the leap from information-knowledge to action-knowledge that constitutes discovery. What matters in this distinction is that alertness leads to the acquisition of knowledge, and not the other way around. Kirzner even argues that alertness is a necessary and a sufficient condition for the generation of action-knowledge. But the problem of causation persists because alertness is simply assumed in this distinction. Relevant knowledge that might cause alertness is ruled out.

Recall that this is a theory of how alertness could appear at all: how and what "switches on the entrepreneurial antennae" (Kirzner, 1985, p. 109). But if the entrepreneur is passive prior to being alert, then the properties of alertness cannot explain the change from a non-alert to an alert state of mind. If, as it appears he does, Kirzner wishes to treat entrepreneurial incentives as exogenous variables that influence the market process, it becomes difficult to explain this "paradox" of causation, as he terms it (Kirzner, p. 108).

The ambiguity regarding causation can be seen in another example of Kirzner's, wherein he likens profit opportunities to "spontaneously generated flashing red lights alerting hitherto unwitting market participants to the possibility of pure entrepreneurial profit or the danger of loss" (Kirzner, 1992a, p. 151; emphasis in original). It is not obvious from examples such as this exactly what the relationship of individuals, opportunities, and alertness consists in. Certainly, this example might imply the possibility of costs, preexisting knowledge, alertness, special traits, and so on, even though Kirzner rejects these possibilities. But the intended meaning of the metaphor becomes confusing when we eliminate these conditions. It also risks separating alertness from any sort of real-world human behavior by eliminating ubiquitous conditions of behavior. Cowen (2003) makes a similar objection, pointing out that alertness is not costless because it necessarily involves other behavior that does have a definite cost. For example, noticing a profit opportunity in the street may be costless, but walking down the street certainly is not. Cowen, thus, concludes that Kirzner's theory, when pushed to its logical conclusions, must become simply a theory of search. Fiet (2002, p. 101) further argues that alertness is not only costly, but possibly more costly than search because it is, to some extent, a matter of luck (Demsetz, 1983), with a low probability of success.

In exploring this issue, Foss and Klein argue that Kirzner's theory fails to adequately explain the antecedents of entrepreneurial activity. As they point out, "[b]eyond specifying general disequilibrium conditions ... Kirzner offers no theory of how opportunities come to be identified, who identifies them, and so on; identification itself is a black box" (Foss \& Klein, 2010). So we are left without a necessary explanation of how entrepreneurial incentives actually work. Kirzner appears to recognize the tension in his incentive theory: 
After all, we cannot deliberately search for something of whose very existence one has no inkling. . . . But it does seem intuitively obvious that alertness can be 'switched off' by the conviction that external intervention will confiscate (wholly or in part) whatever one might notice. Surely what excites one antenna to 'see' that which has hitherto entirely escaped one's attention, is the general sense that something of value may be within reach, if only one knew what it was. Surely, it is the general prospect of pure entrepreneurial profit available for the taking that inspires entrepreneurial alertness. Public policies which to any degree deaden the excitement inspired by the prospect of pure entrepreneurial profit, must surely, lower the level of entrepreneurial alertness. (Kirzner, 2009; emphasis in original)

This passage shows that Kirzner really is assuming something about entrepreneurs' knowledge prior to being made alert: Entrepreneurs are aware from the outset that profit opportunities exist. Consider also this comment: "For the sequence of entrepreneurial discoveries that constitutes the market process, the system of incentives is spiced and sharpened by the awareness that market opportunities are to be found only where they have been overlooked by others" (Kirzner, 1985, p. 87; emphasis added). This adds an additional wrinkle to the theory because it appears now that entrepreneurs have knowledge of, or alertness to (in the quotation, "awareness"), the existence of opportunities which allows them to be made alert. Adding to what was said earlier in this section about general knowledge, remember that while Kirzner does not wish to explore the roots of alertness, he does claim they exist and are the source of the entrepreneur's insight. If one starts with knowledge or alertness as some sort of given, however, this appears to assume what one needs to prove. This is still true even if we take into consideration that the "awareness" in question is only of the general existence of some profit opportunities, and not of any particular opportunity (this general existence would presumably apply to all actors, and thus would not explain why particular entrepreneurs discover particular opportunities).

The assumption of general knowledge introduces a tension into Kirzner's writing. Compare the assumption in the above with the claim that discovery always involves surprise (Kirzner, 1997a). But if one is always generally on the lookout for opportunities, what role does surprise really play? It seems one would always have to be surprised by discovery and simultaneously recognize it as the typical result of awareness. It would be a useful subject for future research to discuss the possible conflict in this view.

Whatever the case, for the theory of entrepreneurial incentives to remain viable, entrepreneurs must not only avoid looking for opportunities, they must also be unable to look for them. But if we remove the assumption about the general awareness of profit opportunities, we are left with the problem of causation. It is of course true that some individuals are more aware than others of profit opportunities that exist in the world. Research in opportunity argues that personal knowledge is, in fact, a primary explanation of why some individuals discover opportunities and not others (Shane, 2000, 2003; Venkataraman, 1997). But Kirzner claims that alertness is initially triggered without the effort of the entrepreneur (but nevertheless, through an incentive). This, I argue, is one of the flaws in Kirzner's approach. If we allow for some preexisting entrepreneurial traits that enable the entrepreneur to respond to incentives, then we have a very different question to answer than the one posed by Kirzner.

Kirzner does mention that alertness and the entrepreneurial spirit may be stimulated by, for example, the institutional or cultural environment (Kirzner, 1985, pp. 90-91). I would argue though that this conflates claims about profit opportunities with claims about human action. The institutional environment, for example, is usually described in terms of incentives of the ordinary kind (Laffont \& Martimort, 2002). What is more, these 
incentives are often bound inextricably with individuals' specific knowledge and plans. But Kirzner's theory of entrepreneurial incentives refers not to individuals and their ends but to nonhuman opportunities that exist independent of human beings. In order to use the institutional framework of an economy to explain alertness, Kirzner must provide a specific theory of how institutions provoke alertness in the first place. That is, he needs to first explain the problem of causation identified in this paper. An institutional solution is only a solution if it can grapple with this issue-if it can explain entrepreneurial alertness without recourse to some assumptions regarding knowledge or alertness. Thus, the argument always appears to return to the question of how some people notice things that are unnoticed by others, assuming only exogenous influences. The remarks in this section regarding general knowledge would also apply to the case of institutions. ${ }^{10}$

Likewise, the personal characteristics of the entrepreneur, such as "psychology ... temperament, thirst for adventure, ambition, and imagination" (Kirzner, 1985, p. 26), are individual traits that might explain how an individual seeks to discover opportunity, but not how opportunity makes itself visible to the entrepreneur. ${ }^{11}$ These traits may certainly explain superior vision and judgment of an already-alert entrepreneur, but they do not explain Kirzner's exogenous opportunities theory. Search and its associated costs are a part of ordinary incentives, not entrepreneurial ones. If search is, therefore, excluded by definition as a cause of original alertness, it cannot be used to explain it. The theory of entrepreneurship (whether psychological or economic) often explores how individual traits are incorporated in the search and discovery efforts of the entrepreneur, and they are significant in this light. But they do not meet the criteria for entrepreneurial incentives put forward by Kirzner.

Kirzner has another method of approaching this conundrum. He argues that the value of the opportunity itself provides sufficient impetus for it to be noticed. As he claims, "[h]uman beings tend to notice that which it is in their interest to notice" (Kirzner, 1985, p. 28; emphasis in original). ${ }^{12}$ More specifically, " $[i] n$ order to 'switch on' the alertness of a potential discoverer to socially significant opportunities, they must offer gain to the potential discoverer himself' (Kirzner, p. 29; emphasis in original). This argument is often discussed in reference to the question whether or not entrepreneurship is an equilibrating force. ${ }^{13}$ This question falls outside the scope of this paper. Rather, I take these claims in a narrower sense, as explanations of the appearance of alertness. They too cannot explain the problem we have been investigating. The question remains: What is the connection between opportunity and alertness if the entrepreneur starts from a position of passive non-alertness? Put another way, some critics point out that:

10. Kirzner (1982; 1985, pp. 110-111) uses the notion of entrepreneurial incentives to criticize economic policies, such as the taxation of profits, on the ground that such policies would inhibit alertness and stunt development. However, this argument stumbles on the same problem identified throughout: If the theory has difficulty explaining how opportunities cause alertness, how can it explain how non-opportunities cause non-alertness? While this question is important, a full explanation of the relation between government intervention and alertness must be reserved for later research.

11. Although this paper remains largely agnostic on the exact nature of "opportunity," it is critical of the anthropomorphic idea that opportunities think or act, which is implied in the idea of opportunities causing themselves to become visible.

12. Cf. also Kirzner (1985, p. 91).

13. Much has been written on the question of whether entrepreneurial discovery is equilibrating. For a discussion of the controversy, cf. Kirzner (1997a). This paper has a narrower goal in mind: Instead of analyzing the effects of entrepreneurial activity, it examines only Kirzner's argument regarding the impetus to alertness. Market equilibration is an ex-post problem, whereas I wish to address the ex-ante issue of the causes of the movement from a passive to an alert state. 
Kirzner fails to explain ... why some entrepreneurs are 'alert' to profit opportunities while others, who err, are not-despite the presumably equal pull on all of them that is exerted by the profit motive. Why does the alertness of some of them move them from a position of ignorance to one of knowledge, while the alertness of others does not? Kirzner does not answer this question, nor could he within the incentivesbased framework he is using, since the question . . remains . . . epistemological, not motivational. (Evans \& Friedman, 2011)

As a theoretical claim, the in-their-interest-to-notice explanation is suspect. Individuals are by no means bound to notice things that are in their interest, no matter how much they may want to, and it appears odd to ascribe to individuals a tendency to do this. At least, "pure" theory does not suggest that this is the case. The claim is better understood as an empirical generalization.

But even in this view, the statement is troublesome. Certainly, all human beings want to notice things that are of interest to them. But this does not entail that they ever will. The problem of uncertainty cannot be overlooked, as noted by several of Kirzner's critics, such as Rothbard (1985), Hébert and Link (1988), and White (1990). Kirzner responds to this criticism by emphasizing that his theory does take account of uncertainty and entrepreneurial error, and is inextricably bound up with them (Kirzner, 1985, pp. 40-67). ${ }^{14}$ But this does not address the criticism of the present paper. The argument is not that Kirzner's entrepreneur can never be wrong, but rather that one must provide a reason to believe that he will be correct more often than not; that is, that he will "tend" to be right.

There is also an epistemological problem with the claim that entrepreneurs tend to notice things that are of interest to them. The knowledge that a profit opportunity existed is ex-post knowledge (even for arbitrageurs, who in the real world must cope with uncertainty). Prior to successful exploitation, there is no way of knowing whether one's judgment about an opportunity is correct. We cannot know much about the existence of opportunities that are not exploited. But how then can we speak of a tendency to notice opportunities, an idea that implies that the quantity of opportunities noticed is greater than those that remain unnoticed? We require information about the total distribution of opportunities, as well as information about entrepreneurs' judgments, in order to speak of such a tendency. Without knowledge of the quantity of opportunities or something about their distribution, it appears that all we can say is that at a particular time, an entrepreneur succeeded or failed, but nothing about a trend (or lack thereof). This point holds if opportunities are objectively existing, but it has been argued (Foss \& Klein, 2010) that Kirzner is ambiguous on this point, sometimes claiming that profit opportunities are only "metaphorically waiting to be discovered" (Kirzner, 1997b). If opportunities are only metaphorical, however, then there can be no causal relations between them and other phenomena. And we must remember that Kirzner himself identified the problem of causation that permeates his theory, which would appear to conflict

14. Kirzner appears to misunderstand some of his critics' concerns regarding uncertainty. He emphasizes the uncertainty inherent in all human action, endured by all and capable of generating psychic profits and losses. Rothbard (1985), however, refers to uncertainty bearing. This last is taken to mean the ownership of resources devoted to time-consuming production, involving speculative anticipation of consumer demand, and thus capable of yielding money income (profit or loss). This distinction is significant and appears to be overlooked in important studies, such as Hébert and Link (1988, pp. 132-133) and White (1990), which mainly address the first type of uncertainty. Kirzner acknowledges the criticism of Rothbard but does not appear to grasp the distinction (Kirzner, 1992b, 2000, p. 129n33). This may be due to a divergence between Rothbard and Kirzner regarding the purposes of entrepreneurial theory. 
with the metaphorical view of opportunities, further confounding the theory itself. Explicating Kirzner's precise view on this point is a possible path for future research, given the apparent ambiguity.

\section{Problems and Solutions}

Although much of this article is critical, I must emphasize that the arguments presented here are not (nor are they intended to be) a deathblow for Kirzner's theory of the entrepreneur in its broadest sense. However, research focusing on alertness sui generis is questioned insofar as it falls into the difficulties discussed throughout this paper. There are, therefore, two ways out of the dilemma: either the alertness theory can be reformulated with new foundations, or it can be replaced by an alternate approach. A complete resolution to this problem is outside the scope of this paper. Nevertheless, some comments on these possible solutions are in order.

\section{Solutions Based on Opportunity Discovery}

One relevant point to consider is that even if Professor Kirzner is correct about the inability of ordinary incentives to describe entrepreneurial behavior, this does not imply that a special theory of entrepreneurial incentives must, therefore, exist. It might be the case that there simply is no way of discussing alertness in terms of incentives. This would suggest that a different approach than Kirzner's should be adopted. Or, as suggested by Demsetz (1983), the problem of alertness may simply be a matter of pure luck (and therefore outside the scope of economic analysis), and thus not of incentives at all. Fiet (2007) adds that if entrepreneurial alertness is simply a matter of "accidental" discoveries, then it is generally impossible to give any practical advice to real-world entrepreneurs.

It might still be premature though to claim that it is impossible to salvage Kirzner's theory of entrepreneurial incentives. What must be considered further are the foundations of entrepreneurial alertness. To this end, it is more in the spirit of Kirzner's own work to use theoretical and conceptual tools instead of empirical studies. I have already shown, however, that there are several problematic aspects of Kirzner's theory that must be addressed if his work is to be serviceable to theorists. Perhaps the assumptions regarding the entrepreneur's starting point might be changed to allow for special knowledge or innate ability, or some psychological predisposition to alertness. This is one possibility that has been explored in much of the contemporary literature cited throughout this paper.

Several methods have been suggested in the alertness literature that would serve as effective solutions. Some of these are listed in row 3 of Table 2. The most important of these are cognitive theories, which Busenitz and Barney (1997) also suggest are the most fruitful for separating entrepreneurial from nonentrepreneurial behavior. In this vein, Klein (1999) uses the neuroscience-based concept of the "deepself" to explain how there might be different levels of cognition, claiming that the opportunity-alertness causal link might be between these different levels, rather than between external opportunities and internal alertness, as suggested by Kirzner. Klein argues that "deeper" levels of the mind solve optimization problems that cause entrepreneurial epiphany (alertness) at other levels. Valliere (2011) also uses a cognitive approach, arguing that schema theory can explain how alertness can be triggered without search. In this model, an individual's 
schema (or interpretation of events) serves as a lens through which one individual perceives an opportunity, and is the reason he or she perceives it differently than others. Schemata are partly a matter of the individual's personal knowledge though, so this approach might best be thought of as an improvement of Kirzner's.

Baron and Ensley (2006) argue that it is the individuals' ability to recognize patterns in otherwise complex economic events that explains opportunity recognition. Individuals possess particular cognitive frameworks, often based on personal experience and knowledge, which help them discover hidden meaning in external events. This theory can also be understood as a more fleshed-out way of thinking about Kirzner's view of alertness, which posits an exogenous influence making the individual aware of an opportunity, as opposed the application of a "template" to existing, perceived data. A similar argument is found in $\mathrm{Yu}$ (2001), who posits that personal knowledge influences one's interpretation of events, and thus opportunities. These last approaches seem to differ with Kirzner on the issue of personal traits and knowledge, however, because individuals are not passive. Mitchell et al. (2000) also take a cognitive approach, utilizing the notion of "expert scripts," essentially specialized knowledge structures. Expert scripts are acquired through knowledge acquisition and refinement. Once again, this is a solution to Kirzner's difficulty, although it requires abandoning his fundamental assumptions about the link between opportunity and alertness. The specifically Kirznerian approach is not then necessary as a foundation for many of these works, and actually conflicts with them to some extent (see Tables 1 and 2 for a summary of some similarities and differences between these studies and Kirzner's).

Alertness is to some extent an umbrella for a diverse group of theories, Kirzner's being one of them. So one way scholars might overcome the confusion mentioned in this paper would be to differentiate the strands of alertness theory. An important task is to create an effective taxonomy of alertness theories based around the primary causal factor influencing alertness. The argument of this paper is that such an explanation is essentially lacking from Kirzner's theory. Yet other scholars have studied alertness in ways that do provide explanations.

The key to differentiating an alertness theory from Kirzner's is to elaborate on the fundamental causal factor that influences alertness (or in which alertness consists). As discussed in this section, several approaches do just this. For example, the idea that entrepreneurs systematically search provides the fundamental explanation as to why opportunities are discovered (Fiet, 2002, 2007; Fiet \& Patel, 2008). Providing an analysis of search removes the Kirznerian paradox by providing the missing link between opportunity and discovery. Likewise, other research argues that schemata can be the core concept that explains alertness (Valliere, 2011), thus also avoiding the paradox. The same is also true of the expert scripts approach (Mitchell et al., 2000), or some neurosciencebased solutions (Klein, 1999) and others. So long as this link is present and logically consistent, the Kirznerian problem is avoided.

While these types of solutions mitigate the problems with Kirzner's theory, one might say that they are quite original works, and not truly derivative from Kirzner. If, for example, we introduce the concept of search or specialized knowledge, then there is very little of Kirzner's theory that remains. What is left are only a series of common terms that, as far as their standard usage in the literature is concerned, Kirzner insists are not compatible with his approach. This paper has questioned the logical consistency of Kirzner's theory, but the empirical record is relevant too. As discussed above, experiments to show the prevalence or even existence of alertness have thus far been in vain. This brings us to the second path, which the author finds more compelling: to replace the alertness approach with another, potentially more fruitful theory. 


\section{Solutions Based on Opportunity Creation}

The most relevant solution for the problems outlined in this paper may be found in a theory in which entrepreneurs create opportunities rather than discover them (Alvarez \& Barney, 2007; Foss et al., 2007), or at least a theory in which no conflict between discovery and creation exists (Baron \& Ensley, 2006; Berglund, 2007). A variation of this idea is found in Cowen (2003), who applies Kant's aesthetic philosophy to Kirzner's theory in an attempt to show that creativity lies at the root of alertness. In any case, if one adopts these types of theories, one does not have to explain a causal link between opportunities and alertness, and the problems discussed in this paper do not appear. Focus might, thereby, also be shifted to the entrepreneurial function as it was discussed in the history of economic thought (Hébert \& Link, 1988, esp. pp. 83-100).

Taking this sort of view of entrepreneurial activity opens the door to other useful theories of entrepreneurial behavior. For example, the idea of entrepreneurial judgment as expounded by Knight (1933 [1921]) helps explain the uncertain environment that entrepreneurs face, and the difficulty of perceiving and exploiting contingencies, which are heterogeneous and difficult to describe as simple resource allocation problems, thus requiring special talent in decision making to deal with. The advantage of this foundation is that it attempts these tasks without reference to the causation problem of opportunity or having to wrestle with the epistemological status of opportunities.

Sarasvathy (2001) describes an "effectuation" process whereby entrepreneurs with given means creatively explore the possible ends to which means might be put. The process of pursuing opportunities may be influenced by things like the personal traits or knowledge of the entrepreneur, and also by serendipity. It also incorporates unforeseen contingencies which influence the choice of ends. These aspects allow for a less restrictive set of assumptions about what entrepreneurs know or are capable of. This in turn means that the effectuation view can be better used to describe real-world entrepreneurial behavior and opportunity discovery than Kirzner's view. By involving decisions about ends, however, this approach moves sharply away from the Kirznerian view that entrepreneurship is costless, and thus does not involve ordinary incentives.

Effectuation does not, however, reduce entrepreneurship to simple maximization behavior (a possibility that would certainly distress Kirzner) because it emphasizes the open-ended nature of entrepreneurial decision making. This type of creation "enables the realization of several possible effects . . . but it also allows a decision-maker to change his or her goals and even to shape and construct them over time, making use of contingencies as they arise" (Sarasvathy, 2001; emphasis in original). Costs and benefits may, thus, be taken into consideration by entrepreneurs, but entrepreneurs are also not slaves to a constrained optimization problem. The effectuation view, thus, also paves the way for the spontaneous emergence of welfare-enhancing entrepreneurial behavior. It has been argued, however, that effectuation theory assumes that entrepreneurs control their environment, and thus implies automatic success (Fiet et al., 2005). What is required then is a theory that allows us to introduce the concept of failure. This can be done by viewing entrepreneurship as decision making within the context of uncertainty in the Knightian sense.

If we pursue this line of reasoning, what emerges is a theory of opportunity creation and the entrepreneurial judgment that drives it. The judgment-based theory, largely stemming from Knight (1933 [1921]), attempts to explain the successful exploitation of opportunity through analyzing the entrepreneur's ability to cope with decision making in the face of uncertainty. Foss and Klein (2012) further explore this approach, integrating it with the contemporary literature on entrepreneurship and the theory of the firm. While 
some research questions whether the effectuation and judgmental decision-making approaches are compatible (Sarasvathy \& Read, 2011), others argue that the similarities are stronger than the differences (Foss \& Klein, p. 95).

One important implication of this theory is that it does not preclude the possibility of entrepreneurial search efforts. Even though entrepreneurs might be thought of as creating, effectuating, or realizing opportunities, as opposed to discovering them, it is still possible that they might use specific knowledge to aid them in this task. They might, for instance, limit their creative efforts to some set of activities in which they possess comparative skill (Fiet, 2002; Fiet et al., 2005). Unlike in Kirzner's view, there is no inherent conflict between the judgment approach and many theories of search. Any apparent tension disappears once we discard Kirzner's notion of the exogenous opportunity causing its own discovery.

This is a promising route for research into a specifically entrepreneurial theory of incentives, although intuitively, such a theory would likely be a branch of "ordinary" incentive theory. The judgment approach provides a model wherein entrepreneurial behavior is costly, and thus possibly explicable in terms of ordinary incentives. In such a model, entrepreneurs can bear uncertainty - that is, can attempt to conquer uncertainty through forecasts and capital investment, and can incur profits or losses to the extent that they do this successfully. In any case, without having to explain passive alertness causally, research into entrepreneurship can move past the "black box" of alertness and into discussions of concrete entrepreneurial decision making (Foss \& Klein, 2010). This critique, therefore, hopes to clear the way for theoretical and empirical work in this field.

\section{Conclusion}

Without altering the current theory, entrepreneurial incentives do not appear to fit within the framework designed for them by Kirzner. We cannot simply take the fundamental causal claims of the theory for granted, and furthermore build a theory of entrepreneurial alertness on them. At the very least, some additional clarification is required as to the exact sort of causal relations that Kirzner proposes. Kirzner (2009) observes that his emphasis on entrepreneurial alertness was merely a stepping stone to explaining the larger theme of the competitive market process and the forces that drive it. Nevertheless, entrepreneurial incentives are prominent in his exposition of entrepreneurial theory, as well as his policy analysis (Kirzner, 1982), and merit serious attention. Exactly how these difficulties are approached and solved will prove important for any research into entrepreneurial alertness, and especially research that explores the differences between entrepreneurial and nonentrepreneurial behavior.

In concluding, I would like to pose several open questions. First, does the theory of the entrepreneur require a specialized theory of incentives? Even if we accept that entrepreneurship is a costless activity, and thus incapable of being analyzed in terms of ordinary incentives, this question is still worthy of attention. It might be the case that there is simply no theory of incentives that can be applied to alertness. Further, is there a clear analytical gain from expressing entrepreneurial activity in terms of an incentive relationship? And if there is such a relationship, does Kirzner's theory hit upon the relevant ideas? It is certainly not impossible that the sort of theory advanced by Kirzner might be useful for the study of entrepreneurship. But as far as Professor Kirzner's work is concerned, it does not appear that we can answer these questions in the affirmative. 


\section{REFERENCES}

Alvarez, S.A. \& Barney, J.B. (2007). Discovery and creation: Alternative theories of entrepreneurial action. Strategic Entrepreneurship Journal, 1(1-2), 11-26.

Baron, R.A. \& Ensley, M.D. (2006). Opportunity recognition as the detection of meaningful patterns: Evidence from comparisons of novice and experienced entrepreneurs. Management Science, 52(9), 13311344.

Berglund, H. (2007). Opportunities as existing and created: A study of entrepreneurs in the Swedish mobile internet industry. Journal of Enterprising Culture, 15(3), 243-273.

Busenitz, L.W. (1996). Research on entrepreneurial alertness: Sampling, measurement, and theoretical issues. Journal of Small Business Management, 34(4), 35-44.

Busenitz, L.W. \& Barney, J.B. (1997). Differences between entrepreneurs and managers in large organizations: Biases and heuristics in strategic decision making. Journal of Business Venturing, 12(1), 9-30.

Chandler, G.N., DeTienne, D., \& Lyon, D.W. (2003). Outcome implications of opportunity creation/discovery processes. In W.D. Bygrave, C. Brush, P. Davidsson, J. Fiet, P.G. Greene, R.T. Harrison, et al. (Eds.), Frontiers of entrepreneurship research (pp. 398-409). Wellesley, MA: Babson College Press.

Cowen, T. (2003). Entrepreneurship, Austrian economics, and the quarrel between philosophy and poetry. Review of Austrian Economics, 16(1), 5-23.

Demmert, H. \& Klein, D.B. (2003). Experiment on entrepreneurial discovery: An attempt to demonstrate the conjecture of Hayek and Kirzner. Journal of Economic Behavior \& Organization, 50(3), 295-310.

Demsetz, H. (1983). The neglect of the entrepreneur. In J. Ronen (Ed.), Entrepreneurship (pp. 271-280). Lexington, MA: D.C. Heath and Co.

Evans, A.J. \& Friedman, J. (2011). "Search" vs. "browse": A theory of error grounded in radical (not rational) ignorance. Critical Review, 23(1-2), 73-104.

Fiet, J.O. (2002). The systematic search for entrepreneurial discoveries. Westport, CT: Quorum Books.

Fiet, J.O. (2007). A prescriptive analysis of search and discovery. Journal of Management Studies, 44(4), 592-611.

Fiet, J.O. \& Patel, P.C. (2008). Entrepreneurial discovery as constrained, systematic search. Small Business Economics, 30(3), 215-229.

Fiet, J.O., Piskounov, A., \& Patel, P.C. (2005). Still searching (systematically) for entrepreneurial discoveries. Small Business Economics, 25(5), 489-504.

Foss, K., Foss, N.J., \& Klein, P.G. (2007). Original and derived judgment: An entrepreneurial theory of economic organization. Organization Studies, 28(12), 1893-1912.

Foss, N.J. \& Klein, P.G. (2010). Alertness, action, and the antecedents of entrepreneurship. Journal of Private Enterprise, 25(2), 145-164.

Foss, N.J. \& Klein, P.G. (2012). Organizing entrepreneurial judgment: A new approach to the firm. Cambridge: Cambridge University Press.

Hébert, R. \& Link, A. (1988). The entrepreneur: Mainstream views and radical critiques (2nd ed.). New York: Praeger.

Herron, L. \& Sapienza, H.J. (1992). The entrepreneur and the initiation of new venture activities. Entrepreneurship Theory and Practice, 17(1), 49-55. 
Jacobson, R. (1992). The “Austrian” school of strategy. Academy of Management Review, 17(4), $782-807$.

Kaish, S. \& Gilad, B. (1991). Characteristics of opportunities search of entrepreneurs versus executives: Sources, interests, general alertness. Journal of Business Venturing, 6(1), 45-61.

Kirzner, I.M. (1973). Competition and entrepreneurship. Chicago, IL: University of Chicago Press.

Kirzner, I.M. (1979). Perception, opportunity, and profit. Chicago, IL: University of Chicago Press.

Kirzner, I.M. (1982). Competition, regulation, and the market process: An "Austrian" perspective. Cato Policy Analysis Vol. 18. Washington, DC: Cato Institute.

Kirzner, I.M. (1985). Discovery and the capitalist process. Chicago, IL: University of Chicago Press.

Kirzner, I.M. (1992a). The meaning of market process: Essays in the development of modern Austrian economics. London, U.K.: Routledge.

Kirzner, I.M. (1992b). Entrepreneurship, uncertainty, and Austrian economics. In B.J. Caldwell \& S. Boehm (Eds.), Austrian economics: Tensions and new directions (pp. 68-102). Boston, MA: Kluwer Academic Publishers.

Kirzner, I.M. (1997a). Entrepreneurial discovery and the competitive market process: An Austrian approach. Journal of Economic Literature, 35(1), 60-85.

Kirzner, I.M. (1997b). The Kirznerian way: An interview with Israel Kirzner. Austrian Economics Newsletter, 17(1), 1-8.

Kirzner, I.M. (2000). The driving force of the market: Essays in Austrian economics. London, U.K.: Routledge.

Kirzner, I.M. (2005). Information-knowledge and action-knowledge. Econ Journal Watch, 2(1), 75-81.

Kirzner, I.M. (2009). The alert and creative entrepreneur: A clarification. Small Business Economics, 32(2), $145-152$.

Kitzmann, J. \& Schiereck, D. (2005). Entrepreneurial discovery and the Demmert/Klein experiment: Another attempt at creating the proper context. Review of Austrian Economics, 18(2), 169-178.

Klein, D.B. (1999). Discovery and the deepself. Review of Austrian Economics, 11(1\&2), 47-76.

Knight, F.H. (1933) [1921]. Risk, uncertainty, and profit. Series of Reprints of Scarce Works on Political Economy No. 16. London: London School of Economics and Political Science.

Laffont, J.-J. \& Martimort, D. (2002). The theory of incentives: The principal-agent model. Princeton, NJ: Princeton University Press.

McMullen, J.S. \& Shepherd, D.A. (2006). Entrepreneurial action and the role of uncertainty in the theory of the entrepreneur. Academy of Management Review, 31(1), 132-152.

Mitchell, R.K., Smith, B., Seawright, K.W., \& Morse, E.A. (2000). Cross-cultural cognitions and the venture creation decision. Academy of Management Journal, 43(5), 974-993.

Patel, P.C. \& Fiet, J.O. (2010). Enhancing the internal validity of entrepreneurship experiments by assessing treatment effects at multiple levels across multiple trials. Journal of Economic Behavior \& Organization, 76(1), 127-140.

Rothbard, M.N. (1985). Professor Hébert on entrepreneurship. The Journal of Libertarian Studies, 7(2), $281-286$. 
Salerno, J.T. (2009). Lionel Robbins: Neoclassical maximizer or proto-praxeologist? Quarterly Journal of Austrian Economics, 12(4), 98-108.

Sarasvathy, S.D. (2001). Causation and effectuation: Toward a theoretical shift from economic inevitability to entrepreneurial contingency. Academy of Management Review, 26(2), 243-263.

Sarasvathy, S.D. \& Read, S. (2011). Without judgment: An empirically-based entrepreneurial theory of the firm. Review of Austrian Economics, doi:10.1007/s11138-011-0170-4

Shane, S. (2000). Prior knowledge and the discovery of entrepreneurial opportunities. Organization Science, $11(4), 448-469$.

Shane, S. (2003). A general theory of entrepreneurship: The individual-opportunity nexus. Cheltenham, U.K.: Edward Elgar.

Shane, S. \& Venkataraman, S. (2000). The promise of entrepreneurship as a field of research. Academy of Management Review, 25(1), 217-226.

Tang, J., Kacmar, K.M.M., \& Busenitz, L. (2012). Entrepreneurial alertness in the pursuit of new opportunities. Journal of Business Venturing, 27(1), 77-94.

Tang, J., Tang, Z., \& Lohrke, F.T. (2008). Developing an entrepreneurial typology: The roles of entrepreneurial alertness and attributional style. International Entrepreneurship and Management Journal, 4(3), 273-294.

Valliere, D. (2011). Entrepreneurial alertness through cognitive schema. Proceedings of the 2nd International Conference on Business and Economic Research, March 14-15, Langkawi, Kedah, Malaysia.

Venkataraman, S. (1997). The distinctive domain of entrepreneurship research. In J. Katz \& R. Brockhaus (Eds.), Advances in entrepreneurship, firm emergence, and growth (Vol. 3, pp. 119-138). Greenwich, CT: JAI Press.

White, L.H. (1990). Entrepreneurship, imagination, and the question of equilibration. In S. Littlechild (Ed.), Austrian economics (Vol. III, pp. 87-104). Aldershot, U.K.: Edward Elgar.

Yu, T.F.-L. (2001). Entrepreneurial alertness and discovery. Review of Austrian Economics, 14(1), 47-63.

Zahra, S.A. (2008). The virtuous cycle of discovery and creation of entrepreneurial opportunities. Strategic Entrepreneurship Journal, 2(3), 243-257.

Matthew McCaffrey is a PhD candidate at the University of Angers, 518 West Magnolia Ave, Auburn, AL 36832, USA.

The author wishes to thank Per Bylund, Jörg Guido Hülsmann, Peter Klein, Jakub Wisniewski, and two anonymous referees for their comments on earlier drafts of this paper. Any remaining errors are entirely the author's. 